\title{
Corrigendum: Genetic Identification of the Central Nucleus and Other Components of the Central Extended Amygdala in Chicken During Development
}

\author{
Alba Vicario, Antonio Abellán, Ester Desfilis and Loreta Medina* \\ Department of Experimental Medicine, Laboratory of Evolutionary Developmental Neurobiology, Lleida's Institute for \\ Biomedical Research-Dr. Pifarre Foundation (IRBLleida), University of Lleida, Lleida, Spain
}

Keywords: Islet1, Pax6, enkephalin, corticotropin releasing factor, bed nucleus of the stria terminalis, fear responses, evolution

\section{A Corrigendum on}

Genetic Identification of the Central Nucleus and Other Components of the Central Extended Amygdala in Chicken During Development

by Vicario, A., Abellán, A., Desfilis, E., and Medina, L. (2014). Front. Neuroanat. 8:90. doi: 10.3389/fnana.2014.00090

In the original article, there is an error related to the identification of corticotropin-releasing factor, as explained next.

When trying to continue our work on the chicken extended amygdala, it came to our attention an error on the identification of chicken 'Corticotropin-releasing factor' (abbreviated CRF or CCRF) in our previous publication. In particular, the sequence we used to synthetize riboprobes in order to analyze brain expression, Genbank accession no. NM_204454, does not correspond to chicken CRF but to its receptor 2 (CRFR2). Therefore, the text mentioning CCRF should refer to cCRFR2. The rest of the results of the article on Pax6, Islet1, Nkx2.1, pENK, SOM, and TH, as well as results on connections, are not affected by this correction.

Below we provide a list of the specific sections that need correction (cCRF should be cCRFR2):

A correction has been made to Results, Expression of cCRFR2, cSOM, and cTH, and Comparison to Other Markers, Paragraph 2. The corrected paragraph is shown below.

At early embryonic stages, there was no expression of cCRFR2 in the subpallium, although this gene was strongly expressed in the medial pallium (not shown). cCRFR2 only started to be weakly expressed in the striatal mantle by E14, and by E18 weak to moderate expression could be appreciated in the Ceov and the peri-INP island field (Figure 8B). The cCRFR2 expression in the striatum, peri INP island field and Ceov largely overlapped with that of cIsletl (compare Figures $\mathbf{8 B}, \mathrm{C}$ ). By E19, a few cells expressing cCRFR2 were also seen in the BSTLd and a moderate number of them were found in SpAr (Figure 5J and Table 3).

Corrections have also been made to the captions for Figure $\mathbf{5}$ and $\mathbf{8}$. The corrected captions are shown below.

Figure 5. Expression of cIslet1, cPax6 and other genes in the embryonic telencephalon of chicken, at the level of the INP and the peri-INP island field. (A-K) Digital images of frontal sections through the telencephalon of chicken embryos (from E14 to E19) hybridized for cIslet1, cPax6, or $c N k x 2.1$ (A-D, H-I) or for the phenotype markers genes cpENK, cCRFR2, or $c T H$ (E-G,J,K). Some of the hybridized sections are also immunostained (brown staining) for calbindin 
TABLE 1 | Expression of several genes in the central extended amygdala and some surrounding areas of chicken at E9-E10.

\begin{tabular}{|c|c|c|c|c|c|c|c|}
\hline E9-E10 & INP & pINP & StC & $\mathrm{CeC}$ & Ce-ov & Pov & BSTLd $^{\mathrm{a}}$ \\
\hline cPax6 & - & $+/++$ & $++/+++^{\mathrm{b}}$ & ++ & - & $-1+$ & $+/++$ \\
\hline clslet1 & ++ & $+/++$ & - & - & $++/+++$ & $-1+$ & + \\
\hline$c p E N K$ & ++ & ++ & +++ & ++ & - & $++/+++$ & +++ \\
\hline cCRFR2 & - & - & - & - & - & - & - \\
\hline
\end{tabular}

-, No signal; -/+, Extremely weak signal, generally restricted to few scattered cells; +, Weak signal; ++, Moderate signal; + + +, Strong signal.

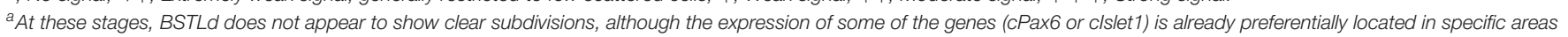
within the nucleus.

${ }^{b}$ Pax6 expression shows a rostrocaudal increasing gradient, from [rostral] ${ }^{\text {low }}$ to [caudal] ${ }^{\text {high }}$.

TABLE 2 | Expression of several genes in the central extended amygdala and some surrounding areas of chicken at E14.

\begin{tabular}{|c|c|c|c|c|c|c|c|c|c|}
\hline E14 & INP & pINP & StC & $\mathrm{CeC}$ & Ce-ov & Pov & BSTLdl & BSTLdi & BSTLdm \\
\hline cPax6 & $-1+$ & $++/+++$ & $-1+++^{a}$ & ++ & $-1+$ & + & $+/++$ & $++/+++$ & $-1+$ \\
\hline clslet1 & ++ & ++ & - & $-1+$ & $++/+++$ & $-/+$ & ++ & $-1+$ & +++ \\
\hline$c p E N K$ & + & ++ & $++/+++$ & ++ & $-/+$ & $++/+++$ & $+/++$ & +++ & +++ \\
\hline cCRFR2 & - & + & - & - & - & - & - & - & - \\
\hline
\end{tabular}

-, No signal; -l+, Extremely weak signal, generally restricted to few scattered cells; +, Weak signal; ++, Moderate signal; + + +, Strong signal.

aPax6 shows a gradiental expression, from [rostrallow to [caudalhigh. Moreover, the expression at rostral levels has declined compared to previous stages.

TABLE 3 | Expression of several genes in the central extended amygdala and some surrounding areas of chicken at E18-E19.

\begin{tabular}{|c|c|c|c|c|c|c|c|c|c|}
\hline E18-E19 & INP & pINP & StC & $\mathrm{CeC}$ & Ceov & Pov & BSTLdI & BSTLdi & BSTLdm \\
\hline cPax6 & $-/+$ & $++/+++$ & $-1+^{a}$ & ++ & $-1+$ & $-1++$ & $+/++$ & $++/+++$ & $-/+$ \\
\hline clslet1 & + & $++/+++$ & - & $-1+$ & ++ & + & ++ & $-/+$ & $+++^{b}$ \\
\hline cpENK & + & $++/+++$ & $+/+++^{a}$ & ++ & $-1+$ & $+/+++^{c}$ & $+/++$ & +++ & +++ \\
\hline cCRFR2 & - & $++^{d}$ & $-1+^{d}$ & $-1+$ & $+^{e}$ & - & + & - & - \\
\hline
\end{tabular}

-, No signal; -/+, Extremely weak signal, generally restricted to few scattered cells; +, Weak signal; ++, Moderate signal; + + +, Strong signal.

aGradiental expression, from [rostral]low to [caudal]high.

${ }^{b}$ Islet1 expression is seen in a compact periventricular area of BSTLdm (adjacent to the Nkx2.1-rich ventricular zone).

${ }^{c}$ The perioval zone is subdivided into a dorsal part rich in pENK and a ventral part poor in pENK.

${ }^{d}$ CRFR2 shows a stronger expression in the lateral part of the striatum, StC, and pINP.

${ }^{e}$ At this age, CRFR2 is only expressed at caudoventral levels of Ceov.

(D) or Nkx2.1 (E). The sections shown are at the level of the INP or the peri-INP island field (pINP). (A-J) are high magnification images of the sections shown in $\left(\mathbf{A}^{\prime}-\mathbf{J}^{\prime}\right)$, respectively. $\left(\mathbf{K}, \mathbf{K}^{\prime}\right)$ show details $c T H$-expressing cells in the striatal capsule (StC) and the rostral part of the subpallial extended amygdala (SpAr). See text for more details. For abbreviations, see list. The arrows in $(\mathbf{C}, \mathbf{D})$ point to a bridge of pallidal cells extending into the globus pallidus, and traversing the INP (this cell bridge expresses $\mathrm{Nkx} 2.1$, but is negative for Islet1). The arrows in $(\mathbf{G}, \mathbf{H})$ point to bridges of striatal cells extending from the lateral striatum into islands of the pINP, and traversing the gobus pallidus. The

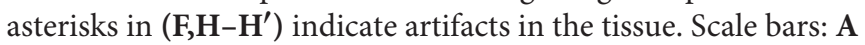
$=300 \mu \mathrm{m}$ (applies to $\mathbf{A}-\mathbf{J}) ; \mathbf{A}^{\prime}=1 \mathrm{~mm}$ (applies to $\left.\mathbf{A}^{\prime}-\mathbf{J}^{\prime}\right) ; \mathbf{K}=$ $400 \mu \mathrm{m} ; \mathbf{K}^{\prime}=200 \mu \mathrm{m}$.

Figure 8. Expression of $c p E N K, c C R F R 2, c S O M$, and $c T H$ in the central extended amygdala of chicken embryos at intermediate or late stages. (A-F) Digital images of frontal sections of the telencephalon of chicken embryos (from E14 to E19), hybridized for the phenotype markers $c P E N K, c C R F R 2$,
cTH, or cSOM. (A-F) are high magnification images of the sections shown in $\left(\mathbf{A}^{\prime}-\mathbf{F}^{\prime}\right)$, respectively. All the sections are at the level of the Ceov and surrounding areas. See text for more details. For abbreviations, see list. Scale bars: $\mathbf{A}=300 \mu \mathrm{m}$ (applies to $\mathbf{A}-\mathbf{F}) ; \mathbf{A}^{\prime}=1 \mathrm{~mm}$ (applies to $\mathbf{A}^{\prime}-\mathbf{F}^{\prime}$ ).

Corrections have also been made to Tables 1-3. The row 'cCRF' has been amended to state 'cCRFR2.' The corrected tables are shown below.

Lastly, corrections have been made to Discussion, All Paragraphs. Any time we refer to our results on 'CRF' in the Discussion section, this should be written as 'cCRFR2' instead.

We sincerely apologize for the inconveniences created by this mistake. This correction only affects minimally the conclusions of the paper, which are mostly based on expression of the transcription factors Pax6, Islet1, and Nkx2.1, and further supported by the expression of pENK and SOM plus some connectivity patterns which are highly conserved between chicken and mouse. Moreover, in a previous study on the 
distribution of CRF immunoreaction in the chicken and quail brains, by Richard et al. (2004), CRF immunoreactive cells were found in some of the same subpallial areas where we described the CRFR2 (in particular, the striatum and the part of the extended amygdala identified by us as the oval central amygdalar nucleus or Ceov). The finding of CRFR2 expression in areas of the chicken brain comparable to the central amygdala is relevant in order to understand the function of CRF related systems and their evolution. In vertebrates, there are two receptors, which bind CRF and urocortin peptides with different affinities (Chang and $\mathrm{Hsu}, 2004)$. In mammals, both receptors show different expression patterns in the brain and outside the brain, and play different roles in stress, anxiety, and motivation (Chalmers et al., 1995; Steckler and Holsboer, 1999; Kishimoto et al., 2000; Henckens et al., 2016). Interestingly, the expression of CRFR2 in the extended amygdala differs between rodents (with variations

\section{REFERENCES}

Chalmers, D. T., Lovenberg, T. W., and De Souza, E. B. (1995). Localization of novel corticotropin-releasing factor receptor (CRF2) mRNA expression to specific subcortical nuclei in rat brain: comparison with CRF1 receptor mRNA expression. J. Neurosci. 15, 6340-6350. doi: 10.1523/JNEUROSCI.15-10-06340.1995

Chang, C. L., and Hsu, S. Y. T. (2004). Ancient evolution of stress-regulating peptides in vertebrates. Peptides 25, 1681-1688. doi: 10.1016/j.peptides.2004.05.022

Coen, C. W., Kalamatianos, T., Oosthuizen, M. K., Poorun, R., Faulkes, C. G., and Bennett, N.C. (2015). Sociality and the telencephalic distribution of corticotrophin-releasing factor, urocortin 3, and binding sites for CRF type 1 and type 2 receptors: a comparative study of eusocial naked mole-rats and solitary Cape mole-rats. J. Comp. Neurol. 523, 2344-2371. doi: $10.1002 /$ cne.23796

Henckens, M. J., Deussing, J. M., and Chen, A. (2016). Region-specific roles of the corticotropin-releasing factor-urocortin system in stress. Nat. Rev. Neurosci. 17, 636-651. doi: 10.1038/nrn.2016.94

Kishimoto, T., Radulovic, J., Radulovic, M., Lin, C. R., Schrick, C., Hooshmand, F., et al. (2000). Deletion of crhr2 reveals an anxiolytic role for corticotropinreleasing hormone receptor-2. Nat. Genet. 24, 415-419. doi: 10.1038/ 74271 between species) and non-human primates: in some rats, the expression is high the amygdalostriatal transition area and the medial bed nucleus of the stria terminalis, moderate in the medial amygdala, and low in the central amygdala (Chalmers et al., 1995; Van Pett et al., 2000; Coen et al., 2015); in contrast, in macaques, the expression is high in the central amygdala, moderate in the medial amygdala, and low in the bed nucleus of the stria terminalis (Sánchez et al., 1999). In view of the inter-species variations, it is necessary to carry out a thorough analysis of the expression of different CRF receptors and their ligands in the brain of more species of mammals and non-mammals, which will help to understand possible differences in the stress response between species.

The authors apologize for this error and state that this does not change the scientific conclusions of the article in any way. The original article has been updated.

Richard, S., Martínez-García, F., Lanuza, E., and Davies, D. C. (2004). Distribution of corticotropin- releasing factor-immunoreactive neurons in the central nervous system of the domestic chicken and Japanese quail. J. Comp. Neurol. 469, 559-580. doi: 10.1002/cne.11023

Sánchez, M. M., Young, L. J., Plotsky, P. M., and Insel, T. R. (1999). Autoradiographic and in situ hybridization localization of corticotropinreleasing factor 1 and 2 receptors in nonhuman primate brain. J. Comp. Neurol. $408,365-377$.

Steckler, T., and Holsboer, F. (1999). Corticotropin-releasing hormone receptor subtypes and emotion. Biol. Psychiatry. 46, 1480-1508. doi: 10.1016/s0006-3223(99)00170-5

Van Pett, K., Viau, V., Bittencourt, J. C., Chan, R. K., Li, H. Y., Arias, C., et al. (2000). Distribution of mRNAs encoding CRF receptors in brain and pituitary of rat and mouse. J. Comp. Neurol. 428, 191-212. doi: 10.1002/1096-9861(20001211)428:2<191::aid-cne1>3.0.co;2-u

Copyright (C) 2021 Vicario, Abellán, Desfilis and Medina. This is an open-access article distributed under the terms of the Creative Commons Attribution License (CC $B Y)$. The use, distribution or reproduction in other forums is permitted, provided the original author(s) and the copyright owner(s) are credited and that the original publication in this journal is cited, in accordance with accepted academic practice. No use, distribution or reproduction is permitted which does not comply with these terms. 